\title{
Optimizing sawing of boards for furniture production using CT log scanning
}

\author{
Original article \\ Author: \\ Magnus Fredriksson \\ Affilation: \\ Luleå University of Technology, Sweden \\ Adress: \\ Forskargatan 1 \\ 93187 Skellefteå \\ Corresponding author: Magnus Fredriksson \\ E-mail: \\ magnus.1.fredriksson@1tu.se \\ Phone: \\ +46910585708 \\ Fax: \\ +46920491399
}

Key words: CT scanning, computer simulation, furniture, process control, Scots pine

Originally published in Journal of Wood Science, Volume 61, Issue 5, pp 474-480.

The final publication is available at http://link.springer.com/article/10.1007\%2Fs10086-015$\underline{1500-0}$ 


\section{Abstract}

The inherent variability of wood material together with sub-optimization in production processes means that a lot of potential value is lost. Computed tomography scanning together with simulation models of the production processes could remedy this, and ensure optimization of the entire production process. Therefore, the purpose of this study was to investigate if such methods can be used to optimize the sawing position of logs in a production process including further processing, in this case crosscutting to make a furniture product with strict quality requirements on dead knots. This was done on 47 Scots pine (Pinus sylvestris L.) logs. The results show a potential yield increase of more than 11 percentage points in the crosscutting operation and more than 4 percentage points when viewing the process as a whole, compared to sawing the logs horns down and centered. 


\section{Introduction}

Production processes in the wood industry usually consist of several process units and activities, especially when further processed products are being manufactured. Furthermore, the variability of the input material to such a process is usually rather high. Many times this leads to sub-optimization (Perstorper et al. [1], Usenius et al. [2]), even in cases where all process units belong to the same company. A system based thinking, where the whole chain is considered when optimizing, would be more efficient in most cases (Beenhakker [3], Pulkki [4]).

In the past decades, sawmills in many countries have become more and more technically sophisticated, and the degree of automation and productivity has increased. In Sweden for instance, the number of sawmills has decreased from almost 300 to around 135 during this period, while the produced volume has increased from around 11 million cubic meters to 16 million cubic meters (Swedish Forest Industries Federation [5]).

Given the increased automation levels and productivity of the wood industry, there is a need to automatically control the processes in the forestry-wood chain in a way that was earlier done manually. One way to do this is through scanning technique and computerized process control systems, and one emerging scanning technique for the wood industry is X-ray computed tomography (CT) scanning.

CT scanning of wood has been used for research purposes for more than two decades (Lindgren [6], Zhu et al. [7], Bhandarkar et al. [8], Moberg [9], Alkan et al. [10], Brüchert et al. [11], Hou et al. [12], Longuetaud et al. [13]). Wei et al. [14] has published a review covering most of the research done on CT scanning of wood up until the year 2010.

High speed CT scanning as a technology for industrial applications has been realized rather recently however (Giudiceandrea [15]). CT scanning of wood has been used extensively in research rather than sawmill applications so far, even if some proposals for a technical solution have been presented (Magnusson Seger and Danielsson [16], An and Schajer [17]). Therefore, it is of interest to propose and investigate different ways of using CT data to control the processes in the wood industry. Studies have shown that CT data can be used to control the sawing process and improve yield (Rinnhofer et al. [18], Lundahl and Grönlund [19], Berglund et al. [20]), but these studies do not investigate the possibility to use CT data for improving yield in a production process involving further processing of the sawn timber. To include further processing in such studies would be beneficial, since it means optimization of a full production process instead of sub-optimizing the activities in it.

The objective of this study was therefore to investigate if the information collected by a CT scanner can be used to control the position of logs during sawing, in order to increase the total yield of a production chain involving both sawing and crosscutting, producing finger-jointed furniture components with certain demands on wood features. If so, the objective was also to quantify this yield increase, and to characterize the logs with a high optimization potential as well as the logs with a low one, with regard to tree and log properties. 


\section{Materials and methods}

The process studied in this paper contains two main activities, sawing of logs and crosscutting of the resulting sawn boards. It is based on the industrial case studied in Broman et al. [21] and Fredriksson et al. [22]. In other words, the process parameters used in this study are based on a real case and a real product, in this case legs for wood cabinets made of Scots pine (Pinus sylvestris L.). In this product, dead knots and large fresh knots are unwanted, something which affects the quality specifications used.

\section{The Swedish pine stem bank}

The study was based on the Swedish Pine Stem Bank which in total contains 712 Scots pine logs (Grönlund et al. [23]). The stem bank trees, from well-documented sites at different locations in Sweden, have been documented thoroughly regarding both tree properties and silvicultural treatments. They have been scanned with a medical CT scanner (Siemens SOMATOM AR.T) to record internal properties such as knots, and also the outer shape of the $\log$ (Grönlund et al. [23]). Knots are described by a parameterized model, which takes into account curvature of the knot and diameter in two log directions, tangential and longitudinal. Each knot is divided into a living part and a dead part. Details on the log and knot models are given by Grönlund et al. [23] and Nordmark [24].

For this study, only logs with a top diameter of 156 to $167 \mathrm{~mm}$ were used. This corresponds to one of the sawing classes in the industrial case study described by Broman et al. [21], where two centerboards of dimensions $50 \times 100 \mathrm{~mm}$ nominal dimensions were sawn. In the study at hand, the same sawing pattern was used. $47 \operatorname{logs}$ from the stem bank fell into the top diameter interval 156-167 mm, and these were subsequently used for this study.

\section{Sawing simulation}

Sawing simulation was performed using the simulation software Saw2003, developed by Nordmark [24]. Saw2003 has been used extensively in earlier research (Lundahl and Grönlund [19], Nordmark [24], Chiorescu and Grönlund [25], Moberg and Nordmark [26]). The input was log models, based on the CT scanned logs of the stem bank. Saw2003 models a sawmill that employs cant sawing with two sawing machines, with curve sawing in the second saw. It is also possible to control positioning of the logs during sawing.

The sawing simulation results in board descriptions with information about knots and wane on the board surfaces. Other board features, such as pitch pockets or rot, are not represented in the stem bank. An example of a log model used in Saw2003 is shown in Figure 1, with outer shape and knots. 


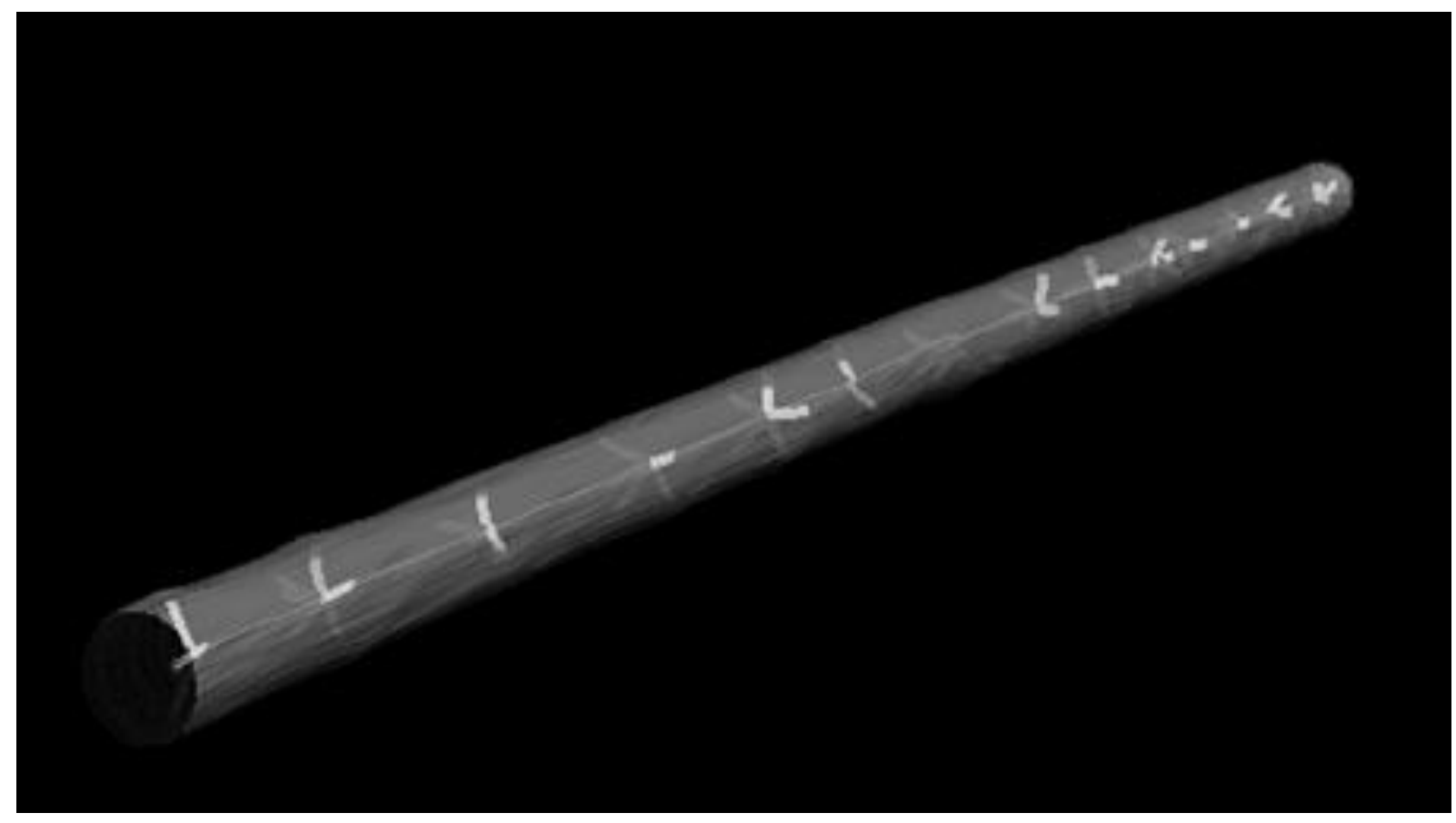

Figure 1. Example of log model used in this study.

\section{Treatments}

The 47 logs were treated in two ways. In treatment HDC (horns down, centered), all logs were sawn horns down and centered. A "horns down" rotational position of a log means that it is sawn with the largest crook upwards in the first saw. The HDC treatment was used as the reference treatment in this study since it is a common practice in many sawmills.

In treatment OPT (optimization), combinations of rotation, parallel positioning and skew were used when sawing the logs. These types of log positioning are described in Figure 2. When a log is rotated, it is turned around its center axis. Parallel displacement of a log means that it is moved in a lateral direction but not turned in any way. When a log is skewed, one end (butt or top) of the log is moved, turning the log around the other end. Rotation can take place in the first saw only, while parallel displacement and skew can be done in both saws. In the second saw, the cant resulting from the first saw is sawn, thus no rotation can be done.

Parallel displacement and skew is achieved by moving log positioners, two in the first saw and two in the second, located at the butt end or top end of the log or cant. In total, five different positioning parameters were tested: Parallel displacement and skew in two saws, and rotation in the first saw. 

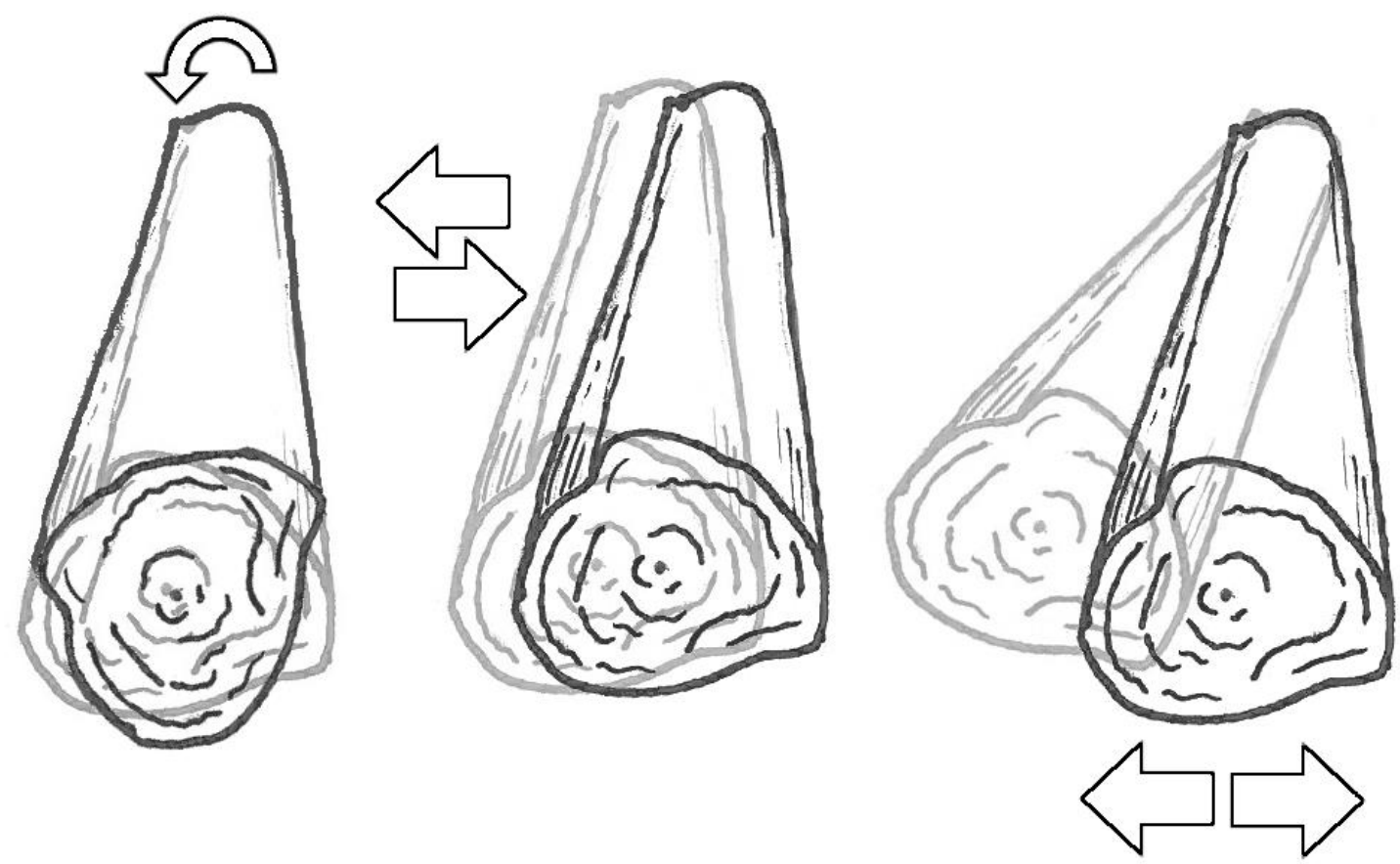

Figure 2. The three types of log positioning studied, from left to right: rotation, parallel displacement, and skew.

The logs were rotated from a position at $0^{\circ}$, which corresponds to the rotational position were the log was scanned, to a position at $170^{\circ}$, in $10^{\circ}$ steps. Since the sawing pattern was symmetrical, all other rotational positions from $180^{\circ}$ to $350^{\circ}$ result in the same boards as $0^{\circ}$ to $170^{\circ}$, only mirrored. Therefore these positions were not tested. Then, three different positions of the positioners, and all combinations of these, were tested in a range of $\pm 5 \mathrm{~mm}$, in $5 \mathrm{~mm}$ steps. This resulted in $18 \times 3^{4}=1458$ simulations per $\log$, and this choice of positions was made as a compromise between available computational time and attempting to test as many positions as possible. The range chosen is reasonable when looking at results obtained by a previous study by Fredriksson [27], however in that study a range of $\pm 14 \mathrm{~mm}$ was used, in 7 $\mathrm{mm}$ steps. The more narrow range of $\pm 5 \mathrm{~mm}$ was chosen in the study at hand, given the relatively smaller diameters of logs used here. Since all combinations of positioner positions were tested, both parallel displacement and skew were achieved.

Treatment HDC resulted in one pair of centerboards from each log, i.e. 96 boards in total. Treatment OPT resulted in 1458 board pairs for each log, i.e. 139968 boards in total.

\section{Crosscutting simulation}

A crosscutting simulation tool developed by Fredriksson et al. [22] was used to model crosscutting of the sawn boards that were the result of the sawing simulation. The tool is capable of crosscutting boards, given a product specification with limits on sizes of knots and wane. The outcome is value-optimized, and based on a value of each product set by the user.

The boards from treatment HDC and treatment OPT were all crosscut using the same settings. Following the industrial case described in Broman et al. [21], the target product was pieces for subsequent fingerjointing and production of cabinet legs, so it was a product with flexible 
length. Allowed lengths of crosscut pieces were 170-550 mm. Pieces 170-285 mm were valued differently from pieces $285-550 \mathrm{~mm}$ for the sake of optimization. If the value of 170 $285 \mathrm{~mm}$ pieces was normalized to 100 , the relative value of pieces $285-550 \mathrm{~mm}$ was 103 . The reasoning behind this was to produce more of longer lengths, which are easier to handle in the production process. Board features were classified as either accepted or rejected depending on a set of quality rules defined in Table 1 . In case both quality limits for length and width were exceeded, the feature was considered as a defect and was cut away. This means that a sound knot of e.g. $48 \times 65 \mathrm{~mm}$ would be considered as accepted, while a sound knot of $52 \times 55 \mathrm{~mm}$ would not. The rest of the defect-free wood was considered accepted, as long as there was a $15 \mathrm{~mm}$ knot-free zone at the end of each crosscut piece.

For each board pair and for the two treatments, two types of yield were calculated for comparison, crosscutting yield and log yield. The crosscutting yield $Y_{\mathrm{cc}}$ was calculated as

$$
Y_{\mathrm{cc}}=100 \times\left(L_{\mathrm{out}} / L_{\mathrm{in}}\right)
$$

where $L_{\text {out }}=$ total length of output material (crosscut components), and $L_{\text {in }}=$ total length of input material (the two boards). The total yield $Y_{\text {tot }}$ was defined as

$$
Y_{\text {tot }}=100 \times\left(V_{\text {out }} / V_{\text {in }}\right)
$$

where $V_{\text {out }}=$ total volume of output material (crosscut components), and $V_{\log }=$ total volume of the log from which the board pair was sawn.

The reason for choosing volume or length yield as opposed to value yield was that value changes with other factors than the material and process, thus making value yield results less stable in time. Also, only one product of one single quality was produced, making value yield essentially the same as volume yield.

Finally, the silvicultural information available in the Swedish pine stem bank was used to find which tree characteristics affected the potential yield gain.

\section{Results}

Figure 3 shows the maximum and minimum crosscutting yield $Y_{\mathrm{cc}}$ obtained in treatment OPT and the $Y_{\mathrm{cc}}$ obtained in treatment HDC. The average $Y_{\mathrm{cc}}$ for the optimized situation, i.e. the position giving the maximum yield in treatment OPT, was 76.5\%. The average $Y_{\mathrm{cc}}$ for treatment HDC, sawing logs horns down and centered, was $65.2 \%$. This means a potential yield increase of 11.3 percentage points, when choosing an optimized sawing position instead of horns down and centered. 


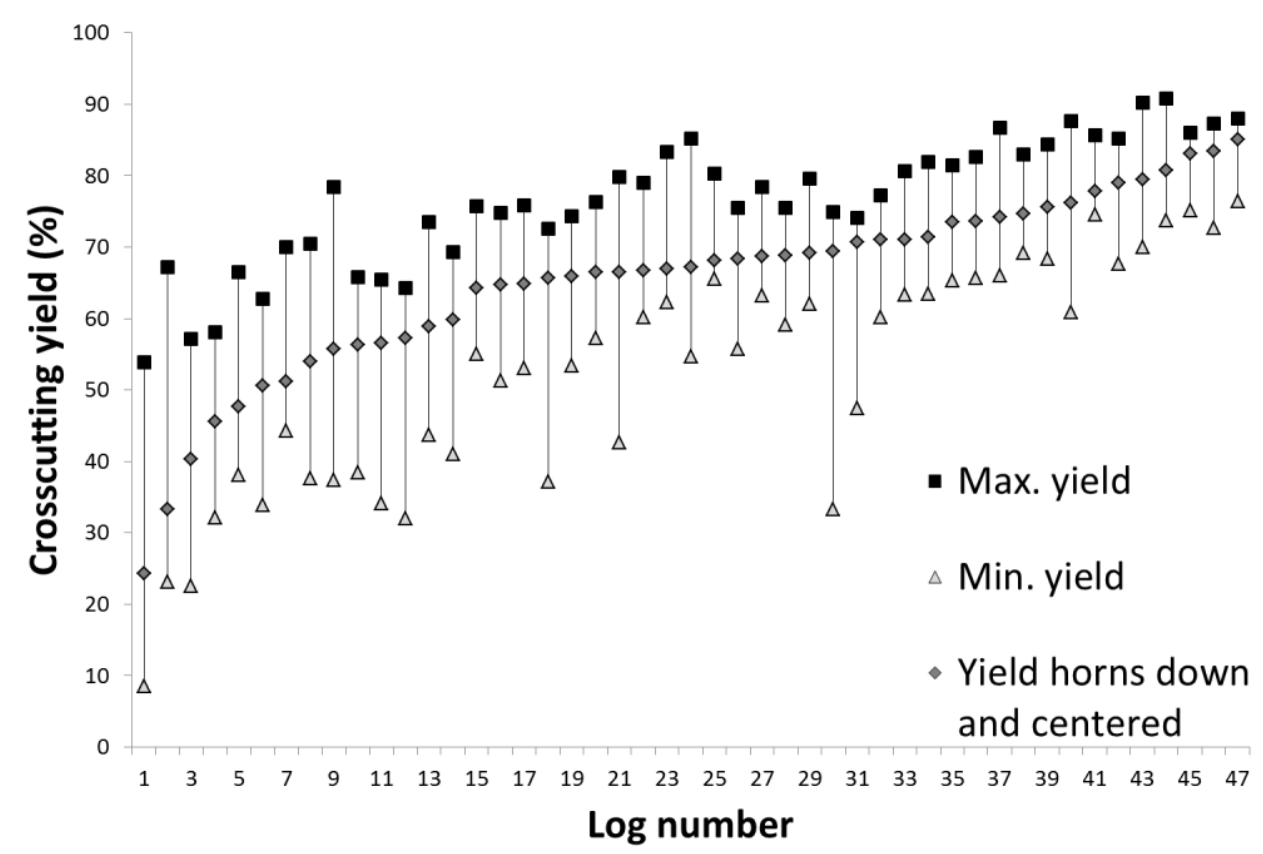

Figure 3. Crosscutting yield $Y_{\mathrm{cc}}$ for the two treatments, and the $47 \operatorname{logs}$. Max. yield is the maximum crosscutting yield obtained when varying rotation, parallel position and skew of the logs (treatment OPT). Min. yield is the corresponding minimum crosscutting yield for treatment OPT. Yield horns down and centered is the crosscutting yield obtained when using treatment HDC. The logs are sorted on Yield horns down and centered, in ascending order.

Figure 4 shows the maximum and minimum total yield $Y_{\text {tot }}$ obtained in treatment OPT and the $Y_{\text {tot }}$ obtained in treatment HDC. The average $Y_{\text {tot }}$ for the optimized situation, i.e. the position giving the maximum yield in treatment OPT, was $30.7 \%$. The average $Y_{\text {tot }}$ for treatment HDC was $26.0 \%$. This means a potential yield increase of 4.7 percentage points. 


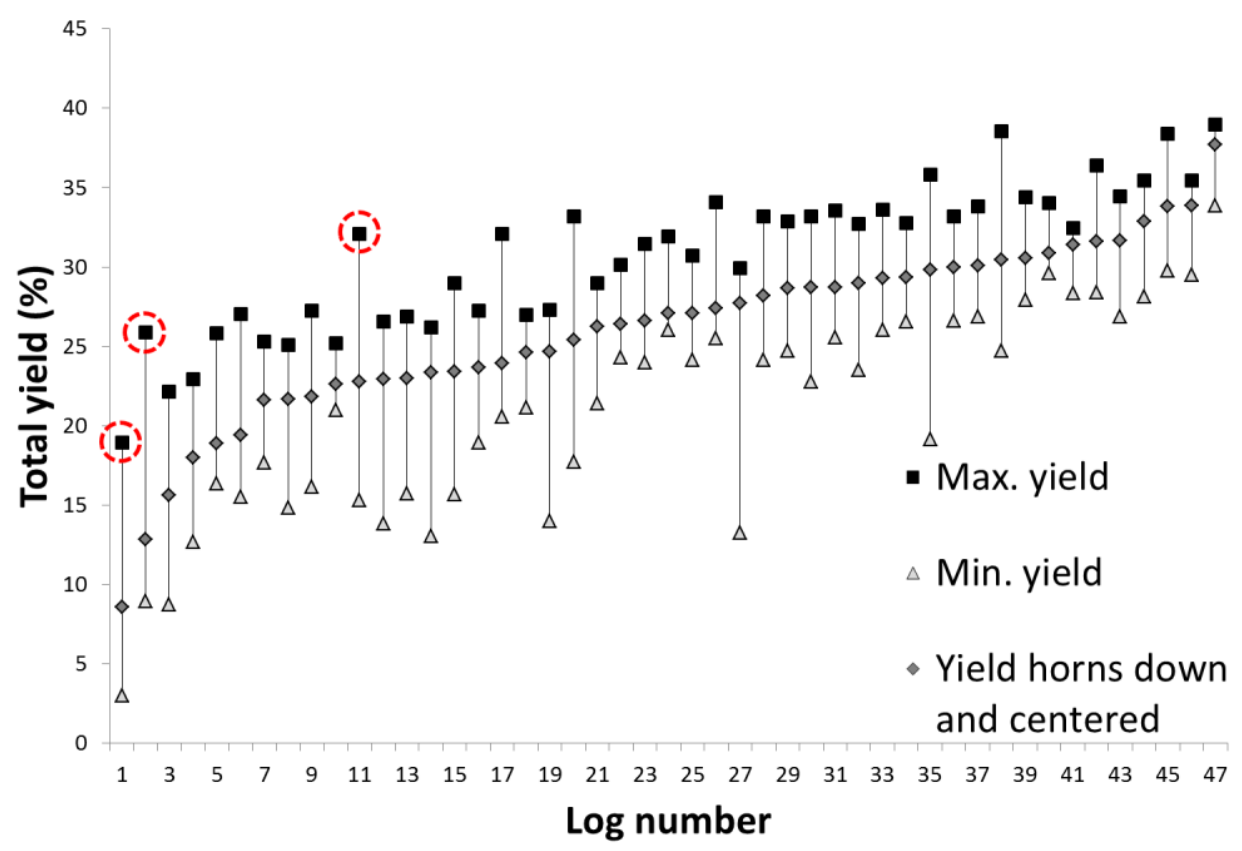

Figure 4. Total yield $Y_{\text {tot }}$ for the two treatments, and the 47 logs. Max. yield is the maximum total yield obtained when varying rotation, parallel position and skew of the logs (treatment OPT). Min. yield is the corresponding minimum total yield for treatment OPT. Yield horns down and centered is the total yield obtained when using treatment HDC. The logs are sorted on Yield horns down and centered, in ascending order. The three logs with the largest potential yield increase have been marked with a circle.

The three logs with the highest potential log yield gain, i.e. the largest difference between the maximum $Y_{\text {tot }}$ in treatment OPT, and the $Y_{\text {tot }}$ for treatment HDC, were logs 1, 2 and 9 in Figure 3. This corresponds to $\log$ 1, 2 and 11 in Figure 4 (marked in Figure 4 with a circle), which means that these logs belong to the logs with rather low yield to begin with. The sample Pearson correlation coefficient $r$ between potential log yield gain and $Y_{\text {tot }}$ for treatment HDC was -0.61 , for all logs of the study. A two-tailed Student's t-test of significance showed that this correlation was significant at the 0.05 significance level.

The silvicultural data from the stem bank (Grönlund et al. [23]) was examined for the trees from which these three logs were cut. What stood out was a rather high age, 138 years in average, and a low site index, which is a measure of site fertility. In this case, the site index (SI100) was calculated as meters of height after 100 years (Grönlund et al. [23]), and the average site index for the three logs was 19.

A sample Pearson correlation coefficient between potential log yield gain and each of the available log and tree features was calculated using all logs in this study, and this is presented in Figure 5. A two-tailed Student's t-test of significance showed that the correlations of Tree age and Site index to the log yield gain were significant at the 0.05 significance level. Values of the probability $p$ for the null hypothesis of zero correlation are included in Figure 5 for all features. 


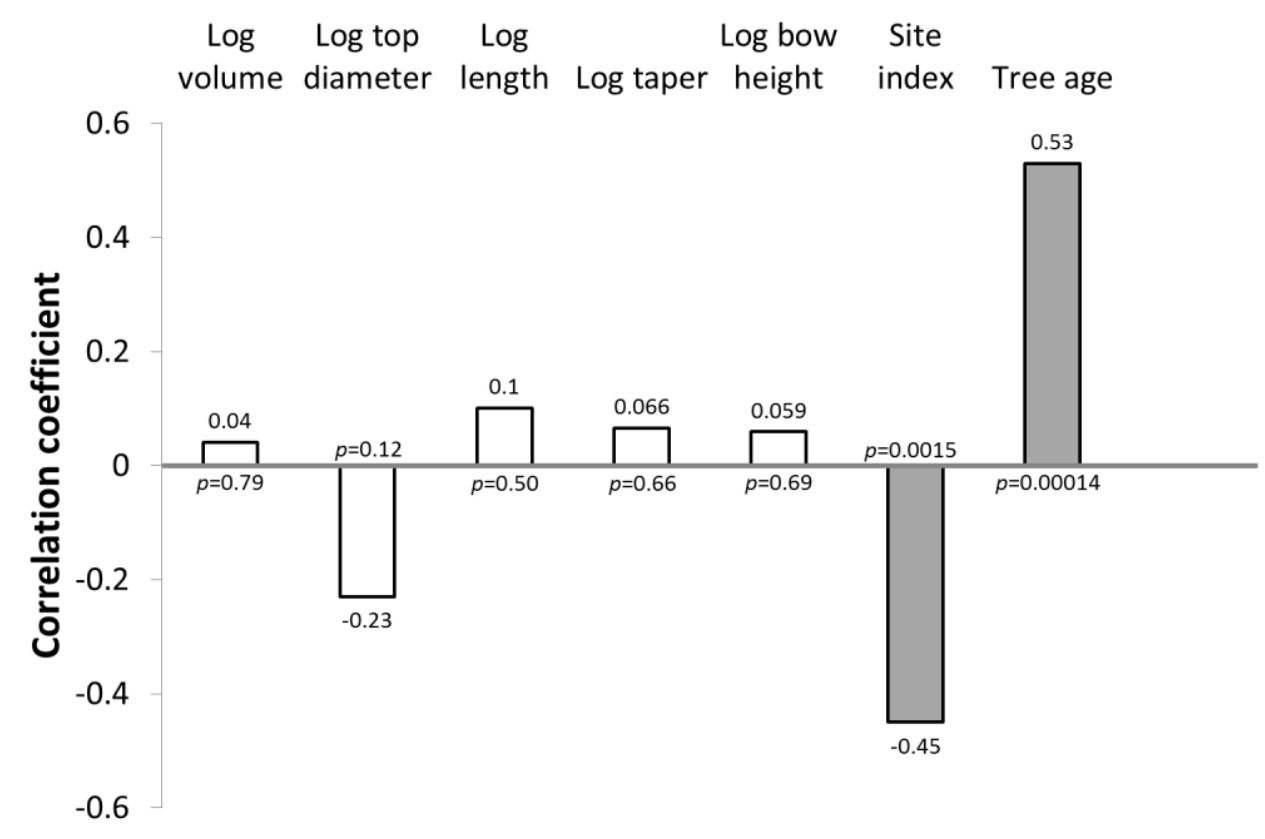

Figure 5. Sample Pearson correlation coefficient $R$ between potential log yield gain and log or tree features, for all $\operatorname{logs}$ of this study. $R$ for each feature is written at the end of each bar. At the beginning of each bar, the probability $p$ of the null hypothesis of zero correlation is presented, for each feature. This probability was obtained by a two-tailed Student's t-test.

\section{Discussion}

This study has shown that it is possible to increase total yield in a furniture production process by 4.7 percentage points, when optimizing the sawing of logs with information on knots inside the logs, and a possibility to simulate both sawing of the logs and crosscutting of the sawn timber. This corresponds to a relative increase of $18 \%$, and this potential increase is in relation to a centered, horns down sawing position. Most of this yield potential is realized in the crosscutting process, even though the controlled parameters are in the sawmill process.

The logs with the highest potential yield gain could be found among the logs with a low yield when sawing horns down and centered. This indicates that the largest possibilities for optimization lies in this type of logs. The (negative) correlation between log yield and potential yield gain for all logs was not high enough to draw any definite conclusions, even if it is significant at the 0.05 probability level, but it points in the same direction. The same is true for log age, which had a positive and significant correlation to potential log yield gain. This is reasonable since the product in question had strict rules for dead knots, something which is found more frequently in older trees than in younger ones. This results in a low yield when not controlling the process with full information on knots, which means increased possibility to optimize the process when such information is available. The latter is the case when a CT scanner is used to scan logs and detect knots inside them.

A possible explanation for the negative correlation between potential log yield gain and site index is that a slow growing tree results in a shorter distance between whorls and a shorter sound knot length (Mäkinen [28], Vestøl and Høibø [29], Moberg [30]), also resulting in lower yield when the sawing is uncontrolled, and therefore a higher potential for optimization. 
The impact of knot size was probably small in this study, since dead knots were not allowed at all, while sound knots had a rather generous size limit of $50 \mathrm{~mm}$.

These characteristics of trees and logs are valid for this case and the quality requirements used here, so it is not a general conclusion for all furniture products. It demonstrates however that scanning and simulation technique can be used to analyze the reasons behind certain results of sawing and further processing of wood. This connects the characteristics of a final product with those of the logs in the logyard and the trees in the forest.

The increase in yield is calculated compared to a centered and horns down sawing position, something which is not always used in sawmills. If an optical log scanner is available for instance, it is possible to optimize sawing based on the outer shape of the log. In this case the yield should increase compared to horns down and centered, but not as much as when full information on knots is available.

The type of optimization investigated in this study, where the solution resulting in the absolute maximum is chosen, might be sensitive to errors in a real process. For instance, the sawing process is not always accurate, and the positioning of the log during sawing cannot be fully controlled (Vuorilehto and Tulokas [31]). Also, the automatic algorithms used to detect knots in a log are not fully accurate either (Johansson et al. [32]). This was beyond the scope of this paper, but if an industrial application were to be realized, a sensitivity analysis should be performed first, and a working solution should be robust enough to handle possible errors.

The data from the CT scanner could also be used for log sorting, so that logs with a low yield even after optimizing could be used for an alternative product. This was also beyond the scope of this paper, but could be considered for a future investigation.

The sawing positions tested were another limitation, and this is something that needs to be overcome in practice. To perform such an optimization that was done in this study at industrial speeds requires faster optimization procedures or a large amount of computational capacity. If more positions where to be tested, together with log sorting, sawing simulation, crosscutting simulation, and optimization, the number of necessary calculations would be very high.

Nonetheless, this study indicates the possibilities of CT scanning combined with computer simulation of several activities in a production process. This results in an integrated viewpoint, where tree and log data are linked to the properties of a final product, in this case legs for a wooden cabinet, to increase yield. All activities in the process were linked together, meaning that the sawing position can be chosen with regard to the total yield in the process, which helps to avoid sub-optimization. All comparisons in this study were made using simulations rather than practical tests, meaning that the absolute results in terms of yield might differ a bit to a real process. However, the relative results should still be valid, given the discussed limitations.

It can be concluded that the potential yield increase when using CT scanning to control a sawing process, with the aim of making a crosscut furniture product with rather high demands 
on dead knots, can be more than 11 percentage points in the crosscutting operation and more than 4 percentage points when viewing the process as a whole. This increase is compared to sawing the logs horns down and centered. It corresponds to a relative yield increase of $17 \%$ and $18 \%$, respectively. Logs with a high yield potential are characterized by a high age and slow growth, while the opposite can be said for logs with a small yield potential.

\section{References}

1. Perstorper M, Pellicane PJ, Kliger IR, Johansson G (1995) Quality of timber products from Norway spruce. Wood Sci Technol 29(3):157-170

2. Usenius A, Song T, Heikkilä A (2007) Optimization of Activities throughout the Wood Supply Chain. In: Blanchet P (ed) Proceedings of the International Scientific Conference on Hardwood Processing, 24-26 September 2007, Quebec City, Canada.

3. Beenhakker HL (1964) Optimization Versus Suboptimization. Int J Prod Res 3(4):317-325.

4. Pulkki R (2001) Role of supply chain management in the wise use of wood resources. Southern Afr For J 191(1):89-95

5. Swedish Forest Industries Federation (2012) Skogsindustrin - en faktasamling. 2012 års branschstatistik. (English title: The forest industry-a collection of facts. Industry statistics of 2012). In Swedish.

6. Lindgren O (1991) Medical CAT-scanning: X-ray absorption coefficients, CT-numbers and their relation to wood density. Wood Sci Technol 25(5):341-349

7. Zhu DP, Conners RW, Schmoldt DL, Araman PA (1996) A prototype vision system for analyzing CT imagery of hardwood logs. IEEE transactions on systems, man, and cybernetics-part B: cybernetics 26(4):522-532

8. Bhandarkar SM, Faust TD, Tang M (1999) Catalog: a system for detection and rendering of internal log defects using computer tomography. Mach Vision Appl 11(4):171-190

9. Moberg L (2000) Models of internal knot diameter for Pinus sylvestris. Scand J Forest Res 15(2):177-187

10. Alkan S, Zhang Y, Lam F (2007) Moisture distribution changes and wetwood behavior in subalpine fir wood during drying using high X-ray energy industrial CT scanner. Dry technol 25(3):483-488

11. Brüchert F, Baumgartner R, Sauter UH (2008) Ring width detection for industrial purposes-use of CT and discrete scanning technology on fresh roundwood. In: Gard WF, van de Kuilen JWG (eds) Proceedings of the COST E53 conference, 29-30 October 2008, Delft, Netherlands.

12. Hou ZQ, Wei Q, Zhang SY (2009) Predicting density of green logs using the computed tomography technique. Forest Prod J 59(5):53-57 
13. Longuetaud F, Mothe F, Kerautret B, Krähenbühl A, Hory L, Leban JM, DebledRennesson I (2012) Automatic knot detection and measurements from X-ray CT images of wood: A review and validation of an improved algorithm on softwood samples. Comput Electron Agr 85:77-89

14. Wei Q, Leblon B, La Rocque A (2011) On the use of X-ray computed tomography for determining wood properties: a review. Can J Forest Res 41(11):2120-2140

15. Giudiceandrea F, Ursella E, Vicario E (2011) A high speed CT scanner for the sawmill industry. In: Divos, F (ed) Proceedings of the 17th International Non Destructive Testing and Evaluation of Wood Symposium, 14-16 September 2011, University of West Hungary, Sopron, Hungary.

16. Magnusson Seger M, Danielsson PE (2003) Scanning of logs with linear cone-beam tomography. Comput Electron Agr 41(1):45-62

17. An Y, Schajer G (2014) Feature-Specific CT Measurements for Log Scanning: Theory and Application. Exp Mech 54(5):753-762

18. Rinnhofer A, Petutschnigg A, Andreu JP (2003) Internal log scanning for optimizing breakdown. Comput Electron Agr 41(1):7-21

19. Lundahl CG, Grönlund A (2010) Increased yield in sawmills by applying alternate rotation and lateral positioning. Forest Prod J 60(4):331-338

20. Berglund A, Broman O, Grönlund A, Fredriksson M (2013) Improved log rotation using information from a computed tomography scanner. Comput Electron Agr 90:152-158

21. Broman O, Fredriksson M (2015) Effect of raw material on yield in a furniture production process. In: Proceedings of the 22nd International Wood Machining Seminar, 14-17 June 2015, Quebec City, Canada.

22. Fredriksson M, Berglund A, Broman O (2015) Validating a crosscutting simulation program based on computed tomography scanning of logs. Holz Roh Werkst 73(2):143-150

23. Grönlund A, Björklund L, Grundberg S, Berggren G (1995) Manual för furustambank. (Manual for pine stem bank) Technical Report 1995:19 Luleå University of Technology. Luleå, Sweden. In swedish.

24. Nordmark U (2005) Value recovery and production control in the forestry wood chain using simulation technique. Dissertation, Luleå University of Technology, Sweden.

25. Chiorescu S, Grönlund A (1999) Validation of a CT-based simulator against a sawmill yield. Forest Prod J 50(6):69-76

26. Moberg L, Nordmark U (2006) Predicting lumber volume and grade recovery for Scots pine stems using tree models and sawmill conversion simulation. Forest Prod J 56(4):68-74 
27. Fredriksson M (2014) Log sawing position optimization using computed tomography scanning. Wood Mater Sci Eng 9(2):110-119

28. Mäkinen H (1999) Growth, suppression, death, and self-pruning of branches of Scots pine in southern and central Finland. Can J Forest Res 29(5):585-594

29. Vestøl GI, Høibø OA (2000) Internal distribution of sound and dead knots in Picea abies

(L.) Karst. Holz Roh Werkst 58(1-2):107-114

30. Moberg L (2006) Predicting knot properties of Picea abies and Pinus sylvestris from generic tree descriptors. Scand J Forest Res 21(S7):49-62

31. Vuorilehto J, Tulokas T (2007) On log rotation precision. Forest Prod J 57(1/2):91-96

32. Johansson E, Johansson D, Skog J, Fredriksson M (2013) Automated knot detection for high speed computed tomography on Pinus sylvestris L. and Picea abies (L.) Karst. using ellipse fitting in concentric surfaces. Comput Electron Agr 96:238-245 